\title{
DIGITAL PERFORMANCE IN V4 COUNTRIES
}

\author{
Dana Kisel'áková \\ University of Prešov, \\ Faculty of Management and \\ Business, \\ Prešov, Slovakia \\ dana.kiselakova@unipo.sk
}

\section{Elena Šrá*}

University of Prešov,

Faculty of Management and

Business,

Prešov, Slovakia

elena.sira@unipo.sk

Beáta Šofranková

University of Prešov,

Faculty of Management and

Business,

Prešov, Slovakia

beata.sofrankova@unipo.sk

* corresponding author

Received: October

2021

Revision: November

2021

Accepted: December

2021

\begin{abstract}
Digital technologies affect our daily lives, whether private or professional. The Covid-19 pandemic highlighted the importance and necessity of digital technologies and the transfer of some activities to the online space. The Digital Economy and Society Index (DESI) monitors Europe's overall digital performance. It is an essential indicator for comparing levels in digital skills and opportunities between EU countries. The aim of the article is to analyze the 3 rd part of this index, namely Use of Internet. On the sample of $\mathrm{V}_{4}$ countries, we analyze the performance of individuals in this area. We analyze the overall DESI in the year 2020. The partial analysis of selected segments of DESI was in the period 2015 - 2020, to show not only the results from the last year, because they may be influenced by the Covid-19 situation, but the countries' progress made by last years. We identify 2 interesting situations. One was in the case of Hungary and the second in Poland. The paradoxes in these countries are fascinating and suitable for further in-depth investigation.
\end{abstract}

Keywords: DESI, use of Internet, digital transformation, V4 countries.

JEL Classification: $\mathrm{O} 33, \mathrm{~A} 13$

DOI: $10.54933 / j m b r p-2021-13-2-1$

Kisel'aková, D., Širá, E., \& Šofranková, B. (2021). Digital performance in $V 4$ countries. Journal of Management and Business: Research and Practice, 13(2). doi: 10.54933/jmbrp-2021-13-2-1 


\section{Introduction}

By joining the European Union, Slovakia has committed itself to the development of the ICT sector, which has been an integral part of the European Union (EU) agenda for more than two decades. Following the eEurope 2002 and eEurope 2005 action plans, the i2010 program was launched as part of the Lisbon Strategy, which focused on the convergence of ICT environments in national countries and creating a unified information environment across the EU. (Ondrejková, 2016)

The progress in the digital economy development is crucial for improving the competitiveness of the EU economy (Kljucnikov, Mura, Sklenár, 2019). To meet all requirements posed by the progress of civilization and increased competition in the economic, social and cultural spheres, calls for selecting appropriate territorial policy also aimed at attaining the objectives of the Europe 2020 strategy (Chapčáková et al., 2019). The need for development policy territorialization was indicated in the Territorial Agenda adopted in 2011, where it was pointed out that the successful implementation of the Europe 2020 strategy depended on taking into account its territorial dimension. The territorialization in such terms can be understood in two ways: the first is the coordination of policies (Suhányi \& Džupka, 2012) and differentiation in space; the second is the use of specific, territoryrelevant capital, should be stimulated by local authorities. (Kwasny, 2018)

In February 2020, the Commission set out its vision for the digital transformation in the communication "Shaping Europe's digital future" to deliver an inclusive use of technology that works for people and respects EU fundamental values (DESI, 2020).

The Digital Agenda for Europe is part of the Europa 2020 strategy. The overall goal of the Digital Agenda is to deliver sustainable economic and societal benefits from the Digital Single Market based on fast and ultra-fast Internet and interoperable applications. (Ondrejková 2016) The Commission responded swiftly to the new challenge by launching several measures in the area of digital. (DESI, 2020)

The current topics of digitalization, informatization, and electronization of public administration are interconnected to such extent that it is difficult to clearly identify the boundaries between eGovernment, the digitalization of society, and smart cities. (Ručinská \& Fecko, 2021)

The transformation of the technological structure of the modern economy has led to the emergence of a digital economy. This fact opens up opportunities and creates some threats. The consequence of this process is the qualitative transformation of economic relations. Attention is increasingly paid to the development of the digital economy and its conceptualization. (Stavytskyy, Kharlamova, \& Stoica, 2019)

In general, the digital economy is not only the relationships mediated by the Internet, cellular communication, and ICT. Among the significant benefits of the digital economy for business, we can include that it affects business interaction and accelerates the course of both the business itself and the various transactions associated with it. It also helps to overcome barriers to entry and provides competitive advantages to companies and ultimately reduces costs. (Stavytskyy, Kharlamova, \& Stoica, 2019)

\section{Theoretical background}

Several indices, scores, indicators, and measurement units describe the status of the digital economy, society, public administration, and they are used as descriptors of digital transformation. The DESI report tracks the progress made by EU member countries concerning their digitalization. It is a widely used and quoted measurement system by experts and policymakers. (Bánhidi, Dobos, Nemeslaki, 2020)

The Digital Economy and Society Index (DESI) monitors Europe's overall digital performance and tracks the progress of EU countries in digital competitiveness. Providing data on the state of digitalization of each Member State helps them identify areas requiring priority investment and action. (DESI, 2020)

The European Commission monitors Member States' digital progress using the Digital Economy and Society Index (DESI) in reports published since 2014. These reports include country profiles as well as thematic chapters. The DESI country reports combine quantitative data obtained from DESI indicators in five areas within the index and an overview of policies and best practices in each country. 
The current COVID-19 pandemic has shown how important digital assets have become for our economies and how networks and Connectivity, data, artificial intelligence, as well as basic and advanced digital skills, support the economy and society by enabling us to continue working and lead the day life even with appropriate restrictions. (DESI Slovensko, 2020)

Table 1. The structure of DESI

\begin{tabular}{|l|l|}
\hline 1 Connectivity & $\begin{array}{l}\text { Fixed broadband take-up, fixed broadband } \\
\text { coverage, mobile broadband and broadband } \\
\text { prices }\end{array}$ \\
\hline 2 Human capital & \begin{tabular}{l} 
Internet user skills and advanced skills \\
\hline 3 Use of Internet
\end{tabular} \\
$\begin{array}{l}\text { Citizens' use of internet services and online } \\
\text { transactions }\end{array}$ \\
\hline 4 Integration of digital technology & Business digitalization and e-commerce \\
\hline 5 Digital public services & e-Government \\
\hline
\end{tabular}

Source: (DESI 2020)

\section{Broadband connectivity}

Access to a fast and reliable broadband connection is crucial in the current context, in which key societal and economic services are delivered online. Everybody needs to have an internet connection in everyday life. Internet is essential in the area of education, in professional work-life, in the case of shopping options, etc. Today, it is a necessity for life for most people in Europe.

\section{Human capital - digital skills}

Digital skills are the backbone of the digital society. They enable people to use digital services and engage in basic activities online, especially when mobility is restricted. The pandemic Covid-19 situation has shown that adequate digital skills empowering citizens to access information and services are crucial for the whole population.

\section{Use of Internet}

During the Covid-19 pandemic, the need to access the Internet proved to people. Whether for work duties or shopping, educating children, and spending free time on entertainment platforms.

\section{Integration of digital technology by businesses}

At present, especially in the context of the ongoing Covid-19 pandemic, companies have had to adapt to the new, resp. changed situation by introducing alternative working conditions. It is difficult for SMEs (including micro-enterprises) with a low level of digital intensity to provide their employees with the opportunity to work from home. One of the main obstacles to the digitalization of SMEs is the digital knowledge gap, which is caused by the low level of digital literacy between owners, managers and employees. Addressing these shortcomings will be necessary to ensure a comprehensive recovery.

\section{Digital public services}

The crisis caused by COVID-19 shows how important it is to ensure the continuation of government activities when social distance measures are in place. A successful strategy to overcome the current pandemic will require large-scale digital public services or improving the functionality of these systems, including eHealth. (DESI, 2020)

\section{Methodology}

We analyzed the whole DESI index divided into 5 primary groups (Connectivity, Human capital, Use of Internet, Integration of digital technology and Digital public services). The DESI contains all 5 areas but in different percentages. DESI overall index is calculated as the weighted average of the five main DESI dimensions: 1 Connectivity (25\%), 2 Human capital (25\%), 3 Use of Internet (15\%), 4 Integration of digital technology (20\%) and 5 Digital public services (15\%).

Because this index contains 5 primary areas, which are very specific, we decided to describe one area more closely. We have chosen the 3 rd area named Use of Internet.

This area, of course, is divided into the following 3 levels, where are analyzed these fields: 
a) Internet use,

b) Activities online,

c) Transactions.

The article aims to analyze the performance in the 3rd part of the DESI index, namely Use of Internet. Therefore, we selected the V4 countries for comparison. The analyzed period was from 2015 to 2020.

The data for analysis were obtained from the official DESI website. For the research, we used the methods of descriptive statistics, such as time analysis, country segmentation, overall DESI analysis, DESI segment analysis, detailed 3rd segment of DESI analysis.

\section{Results}

The performance of the countries during the time is non-uniform. Some countries are advancing more, others less and slower. A comparison of DESI growth and the last score in EU countries is shown in Figure 1. The countries' progress is shown in one of the 4 quadrants, which were created on the basis of the average values of all EU countries. All $\mathrm{V}_{4}$ countries gained the score under the EU average. The most progressive country among the ones we analyzed was Hungary (HU), then Poland (PL). The Czech Republic (CZ) gained the highest score. And Slovakia (SK) gained the lower progress and score.



Figure 1. Digital Economy and Society Index - Member States' progress, 2015-2020 Source: DESI (2020)

The performance of overall DESI in the last year 2020 is shown in Figure 2. We see how the individual segments affect the general index. According to the composition of DESI, we can identify where the country has its weaknesses. Hungary, Poland and Slovakia gained the lowest values in the Integration of digital technology. Human capital and Connectivity are the most represented segments of the DESI. Unfortunately, we must state that none of the $\mathrm{V}_{4}$ countries reached a value higher than the EU average. In all 4 countries, values below the EU average were reached in 2020. 
1 Connectivity

- 3 Use of Internet

5 Digital Public Services
2 Human Capital

- 4 Integration of Digital Technology

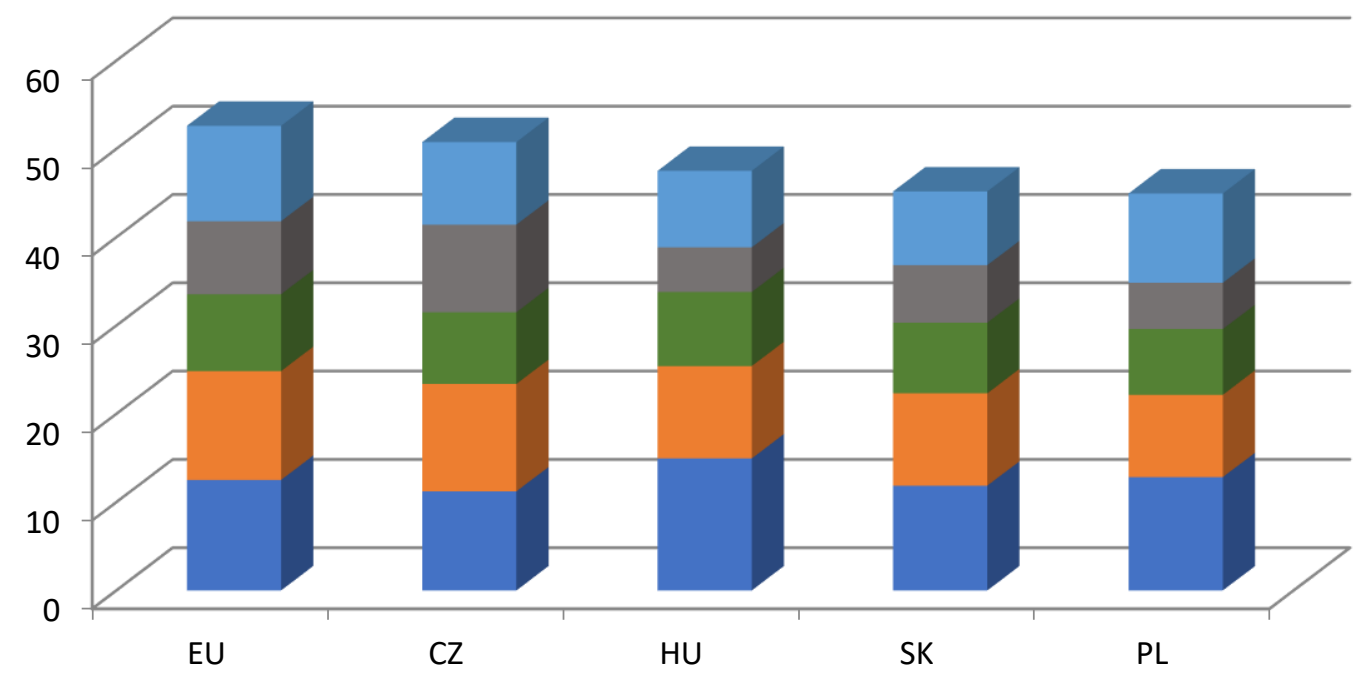

Figure 2. DESI 2020 in V4 countries

Source: DESI (2020)
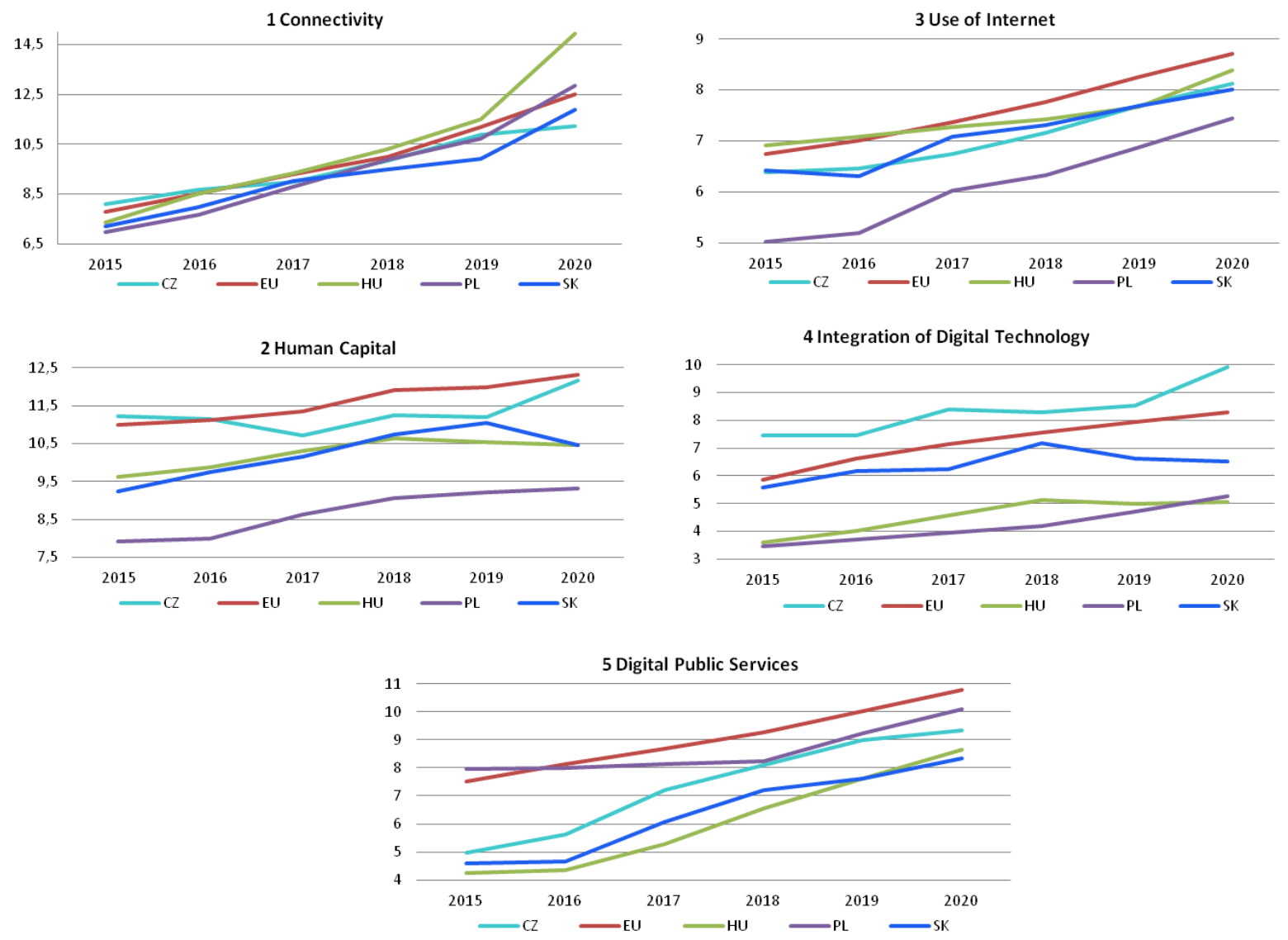

Figure 3. Performance of 5 basic groups of DESI in V4 countries Source: own processing 
However, when we compare the development over time and in the individual segments that make up DESI (Figure 3), we see that the values have an increasing trend. Thus, the situation in the V4 countries is improving from year to year. However, progress in individual DESI segments is not uniform. This also has an overall effect on the lower overall DESI performance.

The most significant increase was in the 1st area of DESI, in Connectivity. It is logical because the other areas cannot increase without the internet connection, e.g., Digital public services. The connectivity segment is also attractive because the differences between the V4 countries and the EU average are the smallest. Hungary has just significantly improved in the last year. In segments 2, 3, and 5, the values for the $\mathrm{V}_{4}$ countries are lower than the EU average. In segment 1, only Hungary is over the EU average. In segment 4, only the Czech Republic is over the EU average.

For a more detailed analysis, we chose 3rd part of DESI, namely Use of Internet. Overall, 3 Use of Internet within DESI in the V4 countries is lower than the EU average. In this respect, Hungary is the leader among the analyzed countries and the weakest is Poland. We are interested in how individuals use the Internet, its availability, and the most common reason for using it. In this respect, we have selected only the individuals. We did not consider the pattern of behavior of enterprises and companies on the Internet.

The 3 rd part of DESI is divided into the following 3 levels, namely 3a) Internet use, $3 \mathrm{~b}$ ) Activities online and 3c) Transactions. Interestingly, there are significant differences in Internet access between the V4 countries (Table 2). Countries with the most households connected to the Internet have, paradoxically, the most individuals who have never used the Internet. In this area, the Czech Republic gained the most points in the DESI index from V4countries (Figure 4), not only in the last analyzed year but in the entire period under review.

3a) Internet use

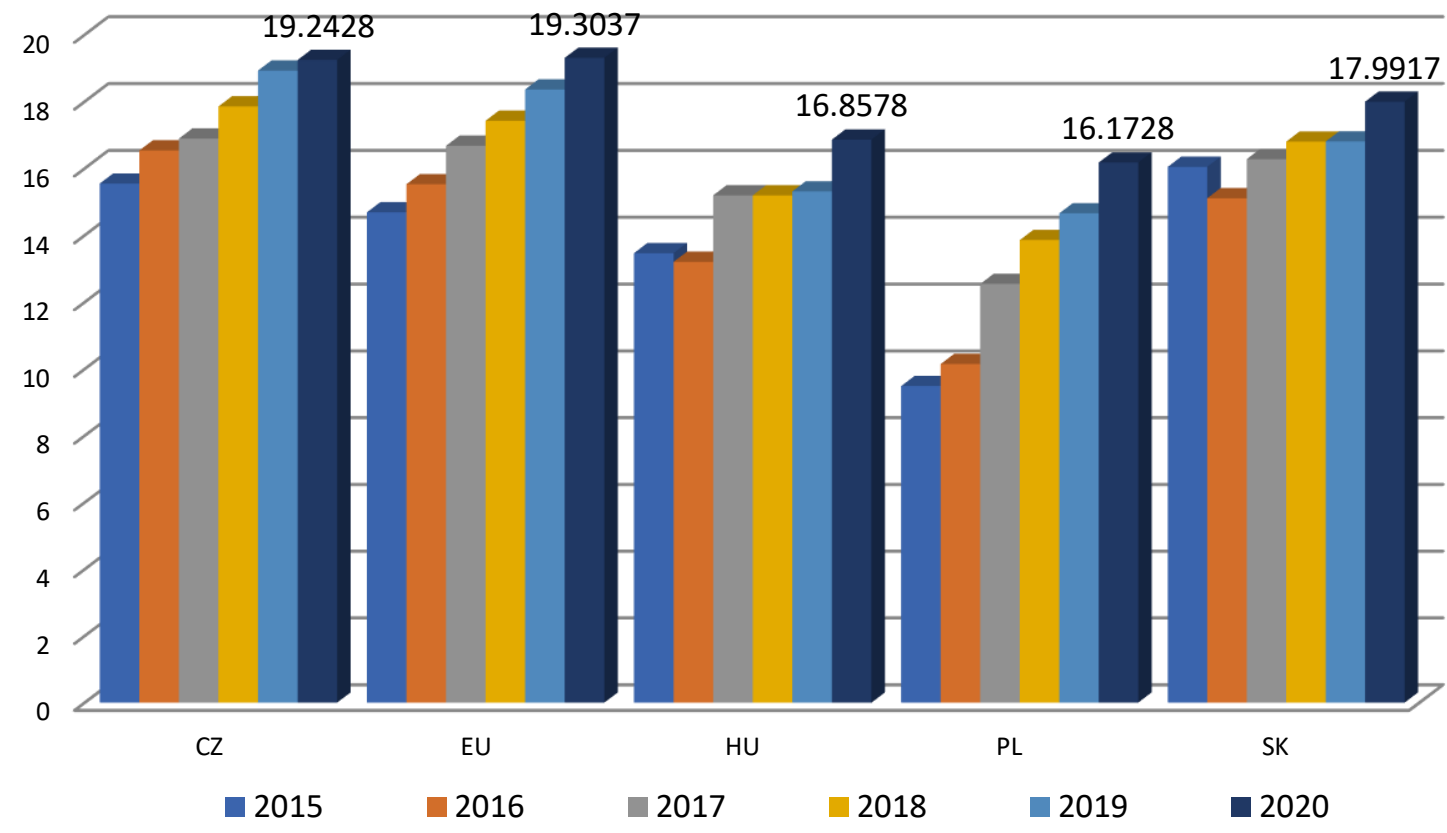

Figure 4. Performance of V4 countries in 3a) Internet use Source: DESI (2020)

Hungary leads again in the 3b) Activities online section (Figure 5). This country is ranked the highest in this respect. Compared to other countries, it also has significantly higher DESI values. But in the 3c) Transactions, Hungary has the lowest values during the whole period. The values of the EU average are very important for comparison. We see that in $3 \mathrm{~b}$ ) Online activities, other V4 countries except for Hungary have lower values. However, the fact that an apparent growing trend of values for all analyzed countries can be seen in the given area remains positive. 


\section{3b) Activities online}

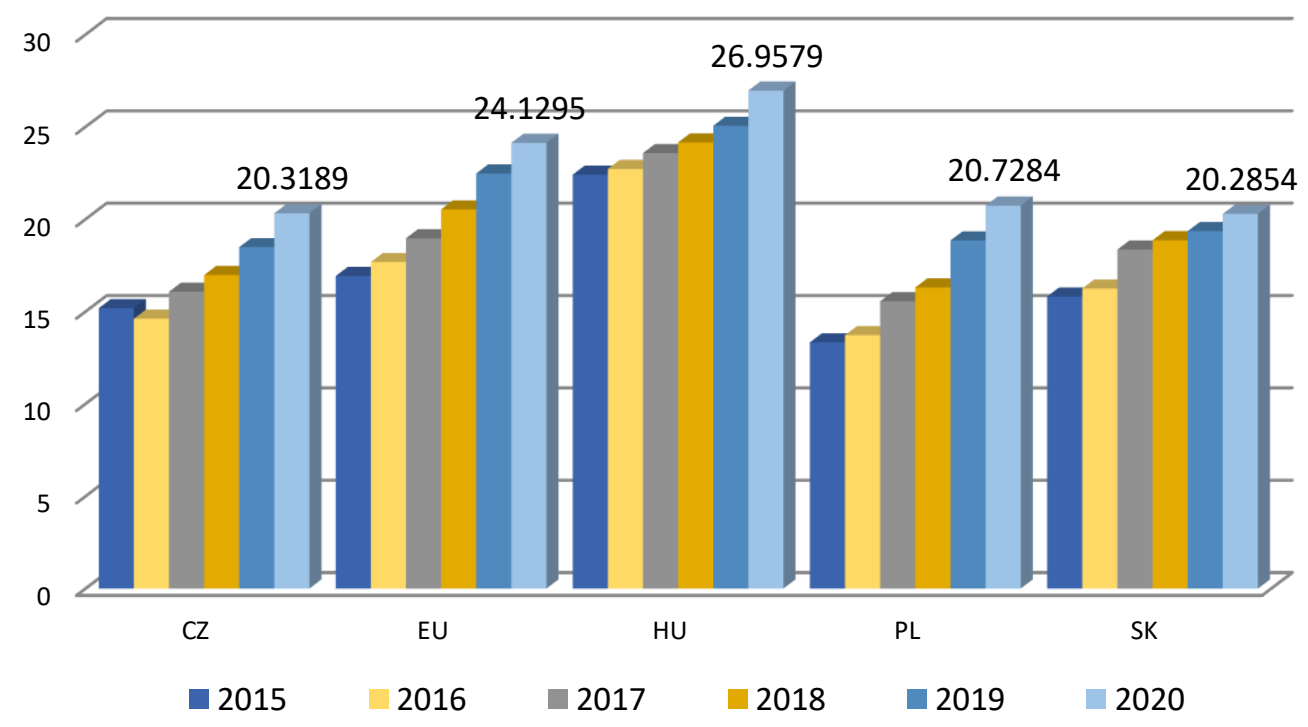

Figure 5. Performance of V4 countries in 3b) Activities online Source: DESI (2020)

In area 3c) Transactions (Figure 6), the highest values during the whole analyzed period, are in the EU average. The positive note is that in the last 2 years, the values in the case of Slovakia have increased significantly and are even higher than the EU average. Also, in the case of the Czech Republic, we can talk about comparable results in the last 2 years.

\section{3c) Transactions}

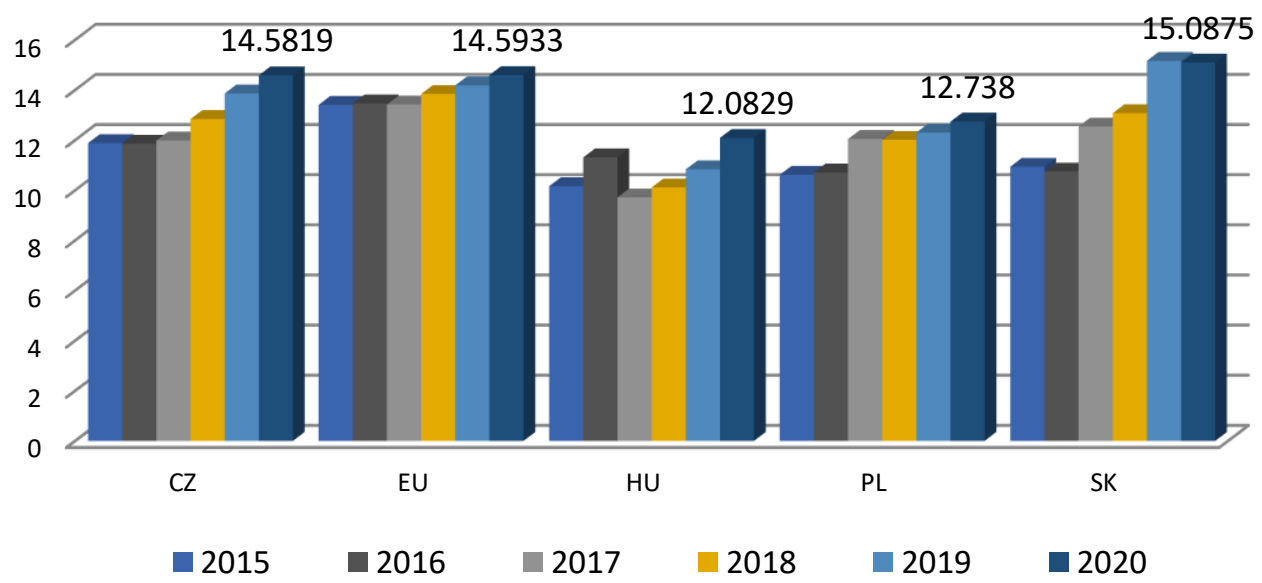

Figure 6. Performance of V4 countries in 3c) Transactions

Source: DESI (2020)

\section{Discussion}

In recent years, we can see that there has been an increase in the monitored indicators in all V4 countries and an increase in EU average values. This is also a consequence of the intensive support in this area in recent years. 
On 19 February 2020, the European Commission approved the "digital package" document. It contains documents setting out the digital policy of the new European Commission. The most important message was the idea that digital technologies would serve everyone. The digital package contains three important documents determining the digital policy of the new European Commission:

- Communication Shaping Europe's digital future.

- Communication on a European Data Strategy.

- White Paper Excellence and Confidence in Artificial Intelligence.

And two accompanying documents:

- Commission report on the safety and accountability implications of artificial intelligence, the Internet of Things and robotics.

- B2G Data Sharing Expert Group Report (Digital agenda, 2021).

The main strategic document is the "Chapeau" Communication Shaping Europe's Digital Future. Based on the priorities and initiatives set out in the document, it can be stated that the new EU digital agenda contains fewer legislative acts. It will focus more on making the digital transformation in the EU a process that Europe will actively shape following its democratic values and on ensuring synergies between the digital transformation and other priority EU policy areas.

The European Data Strategy focuses on the issue of data sharing within the private sector and also the sharing of private sector data with the public sector with a vision to make Europe a leader in the data economy given a large amount of industrial and public sector data at its disposal.

The White Paper on Excellence and Confidence in Artificial Intelligence summarizes this issue in terms of the current EU regulatory environment, as well as in terms of existing EU policy activities and outlines, what issues and to what extent need to be addressed in relation to the future regulatory framework for Artificial Intelligence (Digital agenda, 2021).

In addition to this strategic document, operational actions were taken in various countries in the period 2020-2021, reflecting the requirements that arose from the Covid-19. Due to various restrictions, several institutions have switched to electronic communication. In Slovakia, many municipalities quickly adapted to the changed conditions and began to communicate electronically. Also, in education, online communication has adapted rapidly to common practice through the transition to distance learning. In Poland, also due to the global COVID-19 situation, many companies, not only institutions, are delivering their work remotely (Pilipczuk, 2021).

In addition to the overall EU assistance in the field of computerization and implementation of digital policy, it is crucial to evaluate the specific use of the Internet within the examined sample of countries in our article. It is important to evaluate the reasons for using the Internet because many psychosocial disorders are thought to be related to excessive Internet use. The presence of specific comorbid diagnoses, including mood disorders, bipolar disorders, and social anxiety disorder, are highly represented among groups of excessive Internet users (Yellowlees, Marks, 2007).

In the results and based on the data from Figures 4-6, we can see that the use of the Internet is different. Finally, the question is, what activities are done on the Internet by individuals? Because we see significantly different values in the example of Hungary. Table 2 contains selected indicators that can help us better justify the data obtained above. There are only selected indicators, which we found necessary for our research area.

In areas $3 \mathrm{~b}$ ) and $3 \mathrm{c}$ ), we see the most significant differences in Hungary. $87 \%$ of all internet users spend their time on social networks and communicating with friends in this country. We can conclude from this that in 2020, perhaps also due to the impact of the Covid-19 pandemic, time spent on the Internet was mainly creating social bonds and contacts. Shopping and online banking were used in this country, at least in comparison with other countries. On the contrary, online banking was the most successful in the Czech Republic. In this country, up to $80 \%$ of all internet users used online banking services in 2020.

Another area that became more important, especially during the Covid-19, is the Use of Internet for education. In this respect, we were surprised by the results. Only $15 \%$ of all internet users in Hungary are doing online courses. It was also the highest percentage among the $\mathrm{V} 4$ countries. The lowest $\%$ of all internet users doing online courses was in Poland.

Poland is a specific country which, on the one hand, has the highest coverage and use of the Internet by households, but also the highest number of people who do not use the Internet. These data must also consider that Polish inhabitants spend the least time on activities on the Internet compared to other $\mathrm{V}_{4}$ countries, whether on online banking, education and online courses, or even contacting on social networks. 
Table 2. Selected indicators in V4 countries in 2020

\begin{tabular}{|c|c|c|c|c|c|c|}
\hline & & & $\mathbf{C Z}$ & HU & PL & SK \\
\hline \multirow{2}{*}{ Ð } & $\begin{array}{l}\text { Households with access to } \\
\text { internet at home }\end{array}$ & $\begin{array}{l}\text { \% of all } \\
\text { households }\end{array}$ & 88 & 88 & 90 & 86 \\
\hline & $\begin{array}{l}\text { Individuals who have never } \\
\text { used the Internet }\end{array}$ & $\begin{array}{l}\text { \% of all } \\
\text { individuals }\end{array}$ & 8 & 12 & 13 & 7 \\
\hline \multirow{3}{*}{ 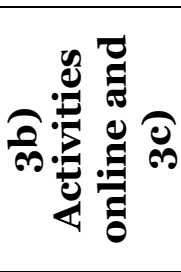 } & $\begin{array}{l}\text { on-line banking - } \\
\text { individuals }\end{array}$ & $\begin{array}{l}\text { \% of internet } \\
\text { users }\end{array}$ & 80 & 61 & 59 & 65 \\
\hline & $\begin{array}{l}\text { Doing an on-line course - } \\
\text { individuals }\end{array}$ & $\begin{array}{l}\text { \% of internet } \\
\text { users }\end{array}$ & 11 & 15 & 8 & 10 \\
\hline & $\begin{array}{l}\text { Participating in social } \\
\text { networks - individuals }\end{array}$ & $\begin{array}{l}\text { \% of internet } \\
\text { users }\end{array}$ & 67 & 87 & 66 & 72 \\
\hline
\end{tabular}

Source: own processing according to Digital agenda data (2020)

\section{Conclusion}

The Digital Economy and Society Index monitors Europe's overall digital performance. Its values reflect the country's overall state in the Use of Internet and technology, not only by the population but also by corporations and government at the same time. DESI contains a summary of several areas and aspects. It is good that we can value the current situation in a given country with one DESI value. But, on the other hand, it is not good to rely only on the overall value of DESI but also to examine its components. Because if a country shows problems in any of the areas surveyed, it will affect the overall assessment.

DESI consists of 5 basic areas, each of which again consists of several parts and a large number of indicators and variables enter into the calculation. However, we decided to analyze only one in more detail for the above reasons, namely the 3rd area from DESI.

In analyzing this section, we have identified in more detail the differences between countries as well as within a country. Surprising findings were made in Hungary, where most internet users were concentrated on social networks. Here we have the opportunity for further research into this phenomenon in a broader context. It would be interesting to examine in more detail the behavior of Internet users in this country, perhaps also with regard to the age and educational structure of the population.

In contrast, the country with the best internet coverage of households, Poland, had the fewest users in the area of Online activities and transactions among the analyzed countries. In this country, a deeper analysis would be needed to understand this current situation, as well as other activities of interest to consumers on the Internet.

To better understand and evaluate the obtained results, it is necessary to subject the remaining 4 areas forming the DESI to a deeper analysis. This could be a suggestion for further research on this issue.

The possible extension of the research sample to other countries or the whole EU could be a topic for further research. The field of the digital economy and the use of information technology, whether for everyday life or business, is very extensive. As can be seen in the summary, there are other possibilities where research can be directed in this area.

\section{Acknowledgment}

This work was supported by the Slovak Research and Development Agency under contract No. APVV-20-0338. 


\section{References}

Bánhidi, Z., Dobos, I., \& Nemeslaki, A. (2020). What the overall Digital Economy and Society Index reveals: A statistical analysis of the DESI EU28 dimensions. Regional Statistics, 1O(2), 42-62.

DESI (2020). Retrieved from https://digital-strategy.ec.europa.eu/en/policies/desi

DESI data (2021). Retrieved from https://digital-agenda-data.eu/charts/desi-see-the-evolution-oftwo-indicators-and-compare-countries

DESI Slovensko (2020). Retrieved from https://www.zmos.sk/download_file_pdf

Digital Agenda (2020). Retrieved from https://digital-agenda-data.eu/charts/country-profiles \#chart

Digital agenda (2021). Retrieved from https://www.mirri.gov.sk/aktuality/digitalnaagenda/europska-komisia-zverejnila-digitalny-balicek/

Chapčáková, A., Hečková, J., Gira, D., Valentiny, T., \& Zbihlejová, L. (2019). Quantification of the selected macroeconomic impacts on the EEA countries competitiveness assessment. Montenegrin Journal of Economics, 15(1), 155-171.

Ključnikov, A., Mura, L., \& Sklenár, D. (2019). Information security management in SMEs: factors of success. Entrepreneurship and Sustainability Issues, 6(4), 2081.

Kwaśny, J. (2018). Multi-level governance concept - complementary role of state in the European Union economies of the $21^{\text {st }}$ century. In: Journal of Management and Business: Research and Practice. 10(1), 12-22. ISSN 1338-0494

Ondrejková, A. (2016). Hodnotenie digitálnej pripravenosti krajín EÚ a postavenie Slovenska. In International scientific days 2016. The agri-food value chain: challenges for natural resources management and society: conference proceeding of reviewed articles (pp. 166-176).

Pilipczuk O. (2021). Transformation of the Business Process Manager Profession in Poland: The Impact of Digital Technologies. Sustainability. 13(24), 13690.

Ručinská, S., \& Fecko, M. (2021). eGovernment and digitalization in the Slovak Republic-Current Development and Political Strategies. In Central and Eastern European eDem and eGov Days (pp. 251-262).

Stavytskyy, A., Kharlamova, G., \& Stoica, E. A. (2019). The analysis of the digital economy and society index in the EU. TalTech Journal of European Studies, 9(3), 245-261.

Suhányi, L. \& Džupka, P. (2012). Management of technological development in res sector and the economic development. In: Journal of Management and Business: Research and Practice. 4(2), 19-30. ISSN 1338-0494.

Yellowlees, P. M., \& Marks, S. (2007). Problematic Internet use or Internet addiction? Computers in human behavior, 23(3), 1447-1453. 